\title{
Cardiac operation under cardiopulmonary bypass during pregnancy
}

Yanli Liu', Fengzhen Han ${ }^{*^{*}}$ (D) Jian Zhuang ${ }^{2 *}$, Xiaoqing Liư ${ }^{3}$, Jimei Chen², Huanlei Huang ${ }^{2}$, Sheng Wang ${ }^{4}$ and Chengbin Zhou ${ }^{2}$

\begin{abstract}
Background: Certain pregnant women suffer from cardiac pathology,and a few of them need cardiac operations under cardiopulmonary bypass during pregnancy. Feto-neonatal and maternal outcomes have not been sufficiently described.

Methods: We conducted a retrospective review of 22 cases of women undergoing cardiac operations under cardiopulmonary bypass during pregnancy in our hospital from Jan.2014 to Mar.2019.

Results: All 22 patients were alive after treatment. The types of cardiac disorders included congenital heart defects, rheumatic heart disease,infective endocarditis,aortic dissection, obstruction and/or thrombosis of a prosthetic valve. Only one case was a twin pregnancy,and the other 21 cases were singletons. Four fetuses died in the utero after surgery. Three patients chose termination of the pregnancy after the cardiac operations: one fetus was detected abnormity of the brain and the other two patients abandoned pregnancy. Fourteen fetuses were alive and born without any abnormity. Two fetuses suffered from neonatal intracranial hemorrhage and died after birth.

Conclusions: Cardiac operation under cardiopulmonary bypass during pregnancy is a challenge for physicians in multidisciplinary teams. Strictly evaluating the indication is vital. On the other hand, some patients can benefit from this management.
\end{abstract}

Keywords: Cardiac operation, Cardiopulmonary bypass, Pregnancy, Outcome

\section{Background}

Heart disease complicates more than $1 \%$ of pregnancies and is now the leading cause of indirect maternal deaths [1]. Pregnancy creates a great burden on the cardiovascular system and can result in decompensation in women with underlying cardiac disease. To minimize the maternal and fetal risks, the first choice of treatment should be medical. In cases that are refractory to

\footnotetext{
*Correspondence: 13725161315@163.com; zhuangjian5413@tom.com 'Department of Obstetrics, Guangdong Provincial People's Hospital, Guangdong Academy of Medical Sciences, No. 106 Zhongshan 2nd road, Guangzhou 510080, Guangdong, China

2Department of Cardiovascular Surgery, Guangdong Cardiovascular Institute, Guangdong Provincial Key Laboratory of South China Structural Heart Disease, Guangdong Provincial People's Hospital, Guangdong Academy of Medical Sciences, Guangzhou, Guangdong, China

Full list of author information is available at the end of the article
}

medical treatment, however, corrective cardiac operations should be undertaken [2]. As the Guangdong provincial obstetrical cardiology intensive care center in China, our hospital has accumulated a significant amount of clinical data of pregnant women with heart disease receiving cardiac operations under cardiopulmonary bypass during pregnancy. To investigate fetoneonatal and maternal outcomes, we conducted this study.

\section{Materials and methods \\ Subject}

We searched in our medical record database from Jan.2014 to Mar.2019. The search terms included "pregnancy", "cardiopulmonary bypass" and "cardiac

(C) The Author(s). 2020 Open Access This article is licensed under a Creative Commons Attribution 4.0 International License, which permits use, sharing, adaptation, distribution and reproduction in any medium or format, as long as you give appropriate credit to the original author(s) and the source, provide a link to the Creative Commons licence, and indicate if changes were made. The images or other third party material in this article are included in the article's Creative Commons licence, unless indicated otherwise in a credit line to the material. If material is not included in the article's Creative Commons licence and your intended use is not permitted by statutory regulation or exceeds the permitted use, you will need to obtain permission directly from the copyright holder. To view a copy of this licence, visit http://creativecommons.org/licenses/by/4.0/ The Creative Commons Public Domain Dedication waiver (http://creativecommons.org/publicdomain/zero/1.0/) applies to the data made available in this article, unless otherwise stated in a credit line to the data. 
operation". We obtained 22 copies of the patients' medical materials containing the entire pregnancy course and fetal outcomes with their consent.

\section{NYHA classes}

The NYHA classification was developed in 1928 to describe an overall cardiac appraisal of the status of a patient with heart disease. It was divided into four classes [3]: Class I: Patients with cardiac disease but without resulting limitation of physical activity. Ordinary physical activity does not cause undue fatigue, palpitation, dyspnea, or anginal pain. Class II: Patients with cardiac disease resulting in a slight limitation of physical activity. They are comfortable at rest. Ordinary physical activity results in fatigue, palpitation, dyspnea, or anginal pain. Class III: Patients with cardiac disease resulting in marked limitation of physical activity. They are comfortable at rest. Less than ordinary activity causes fatigue, palpitation, dyspnea, or anginal pain. Class IV:Patients with cardiac disease resulting in inability to carry on any physical activity without discomfort. Symptoms of heart failure or anginal syndrome may be present even at rest. If any physical activity is undertaken, discomfort increases.

\section{Cardioplegia technique}

Adequate myocardial protection is essential for achieving successful outcomes of any surgical procedure necessitating cardiac arrest. The Del Nido solution (blood and crystalloid mixed formula) was used in all the cardiac operations of our study. The route of administration was antegrade or combined antegrade \& retrograde.

\section{Cardiac surgical procedures}

Corrective cardiac operations consisted of mitral or/and tricuspid valve repair, aortic valve replacement (AVR), mitral valve replacement (MVR), ruptured sinus of Valsalva repair, atrial septal defect closure, ventricular septal defect closure, right ventricle outlet obstruction repair, prosthetic mitral/aortic valve thrombectomy and Betall procedure.

\section{Maternal, fetal and neonatal complications after operation}

The most common maternal complication was arrhythmia after operation. Fetal and neonatal complications included stillbirth, preterm delivery ( $<37$ weeks of gestation), neonatal intracranial hemorrhage and death.

\section{Statistical analysis}

A retrospective analysis was performed. Measurement data and enumeration data were expressed as mean \pm standard deviation (SD) or frequencies.

\section{Results}

\section{Patient general information}

The average age of the patients was $29.5 \pm 5.4$ years, with an age range of 21 to 42 years. Half the patients were nulliparous $(n=12,54.5 \%)$. There was one twin preg$\operatorname{nancy}(n=1,4.5 \%)$ and the other patients were singletons $(n=21,95.5 \%)$. The patient's characteristics are listed in Table 1.

\section{Cardiac surgical procedure, intraoperatory parameters and fetal outcomes}

There were 22 patients with different types of heart diseases who received cardiac operations under cardiopulmonary bypass during pregnancy. The composition and proportion distribution of these patients by the type of heart disease,weeks of gestation during operation, NYHA functional classification, cardiac surgical procedure, intraoperatory parameters and fetal outcomes are presented in Table 1,Table 2 and Table 3.

\section{Feto-neonatal and maternal outcomes}

All 22 patients were alive after treatment. Three cases were complicated by arrhythmia after operations, especially atrial fibrillation, which needed medications. Four fetuses died in the utero after operations. Three patients chose termination of the pregnancy: one fetus was detected a brain abnormity and the other two patients abandoned pregnancy. Fourteen fetuses were alive and born without any abnormity. Two fetuses had complicated neonatal intracranial hemorrhage and died after birth. Feto-neonatal outcomes and mode of delivery are presented in Table 4.

\section{Discussion}

Heart disease is the primary cause of maternal and fetal death in $1-4 \%$ of pregnancies. Pregnancy creates an increased burden on the maternal cardiovascular system and can result in decompensation in women with underlying cardiac disease. To minimize the maternal and fetal risks, the first choice of treatment should be medical. However, in some cases, medical therapy is not always sufficient,and open heart operation might be necessary [4]. In 1958, Leyse and colleagues [5] first used cardiopulmonary bypass $(\mathrm{CPB})$ in a heart operation during pregnancy. After the initial trials, pregnant women have been recognized to tolerate $\mathrm{CPB}$ as well as non-pregnant women, but the effects of $\mathrm{CPB}$ on the fetus have varied [6]. Several review articles, reported the maternal mortality rate ranged from 1.5 to $5 \%$, and the fetal mortality rate has ranged from 16 to $33 \%[4,6]$. Currently, reported maternal mortality for cardiac operations is similar to the mortality rate for non-pregnant female patients [7]. Therefore, CPB during pregnancy has a greater effect on the fetus than mother. In our report, 
Table 1 Patient's characteristics

\begin{tabular}{|c|c|c|c|c|c|c|c|c|}
\hline $\begin{array}{l}\text { Patient } \\
\text { No. }\end{array}$ & $\begin{array}{l}\text { Age } \\
\text { (y) }\end{array}$ & Gravidity & Parity & $\begin{array}{l}\text { Singleton } \\
\text { /twin }(S / T)\end{array}$ & $\begin{array}{l}\text { Weight during } \\
\text { operation }(\mathrm{kg})\end{array}$ & Type of heart disease & $\begin{array}{l}\text { NYHA functional } \\
\text { classification }\end{array}$ & $\begin{array}{l}\text { Weeks of gestation } \\
\text { during operation (w) }\end{array}$ \\
\hline 1 & 32 & 1 & 0 & S & 43 & ASD (PAH accompanied) & $\|$ & $22^{+4}$ \\
\hline 2 & 36 & 4 & 1 & S & 60 & MR (PAH accompanied) & $\|$ & $20^{+4}$ \\
\hline 3 & 33 & 3 & 0 & $\mathrm{~T}$ & 63 & DCRV & $\|$ & $26^{+5}$ \\
\hline 4 & 35 & 5 & 2 & S & 60 & MS (PAH accompanied) & III & $18^{+6}$ \\
\hline 5 & 25 & 1 & 0 & S & 49 & Prosthetic AV stuck & III & $20^{+6}$ \\
\hline 6 & 42 & 3 & 1 & S & 72 & MS (PAH accompanied) & IV & $27^{+3}$ \\
\hline 7 & 30 & 2 & 1 & S & 66 & MS + ASD (PAH accompanied) & $\|$ & $23^{+4}$ \\
\hline 8 & 23 & 1 & 0 & S & 48 & $A R$ & $\|$ & $18^{+1}$ \\
\hline 9 & 29 & 4 & 2 & S & 49 & $\mathrm{IE}+\mathrm{MR}$ & IV & $25^{+5}$ \\
\hline 10 & 24 & 2 & 0 & S & 41 & ASD (PAH accompanied) & $\|$ & $20^{+4}$ \\
\hline 11 & 26 & 1 & 0 & S & 49 & Prosthetic AV stuck & IV & $19^{+5}$ \\
\hline 12 & 28 & 3 & 1 & S & 51 & VSD (PAH accompanied) & $\|$ & $24^{+2}$ \\
\hline 13 & 25 & 4 & 1 & S & 55 & ASD (PAH accompanied) & $\|$ & $22^{+3}$ \\
\hline 14 & 28 & 5 & 0 & S & 57 & Prosthetic AS & $\|$ & $30^{+5}$ \\
\hline 15 & 37 & 2 & 1 & S & 74 & $V S D+A R$ & $\|$ & $20^{+3}$ \\
\hline 16 & 28 & 3 & 0 & S & 47 & ASD (PAH accompanied) & $\|$ & $25^{+3}$ \\
\hline 17 & 36 & 3 & 1 & S & 50 & AD (Stanford type A) & III & $23^{+6}$ \\
\hline 18 & 26 & 2 & 1 & S & 68 & IE & III & 26 \\
\hline 19 & 30 & 1 & 0 & S & 49 & MS (PAH accompanied) & III & 28 \\
\hline 20 & 24 & 1 & 0 & S & 45 & ASD + VSD (PAH accompanied) & III & $25^{+6}$ \\
\hline 21 & 21 & 1 & 0 & S & 48 & $\begin{array}{l}\text { Ruptured sinus of Valsalva of the right } \\
\text { coronary cusp+IE }\end{array}$ & IV & 21 \\
\hline 22 & 25 & 1 & 0 & S & 48 & Prosthetic AS & III & $26^{+4}$ \\
\hline
\end{tabular}

$y$ Year, $k g$ Kilogram, $w$ Week, S Singleton, $T$ Twin, ASD Atrial septal defect, VSD Ventricular septal defect, MR Mitral valve regurgitation, DCRV Double cavity of right ventricle, MS Mitral valve stenosis, $A R$ Aortic valve regurgitation, IE Infective endocarditis, MR Mitral valve regurgitation, $P A H$ Pulmonary artery hypertension, $A D$ Aortic dissection, AS Aortic valve stenosis

the maternal mortality rate was $0 \%$,and fetal mortality rate was $18.2 \%$, as same as the above mentioned reviews.

The present study demonstrated that mitral and/or aortic valve disorders were the most common surgical indications for $\mathrm{CPB}$ during pregnancy, although it has been recognized that coronary arterial disease is increasingly prevalent in gynecological patients [8]. The latter, however, could be managed interventionally in most patients, avoiding the risk associated with CPB for fetoneo-natal outcomes. In our report, the indications for surgical procedure under $\mathrm{CPB}$ during pregnancy consisted of congenital heart defect (ASD, DCRV, VSD), rheumatic heart disease (mitral or aortic valve disorders),infective endocarditis,aortic dissection, obstruction and thrombosis of the prosthetic valve. Seven patients (all with a congenital heart defect)accompanied moderate to severe $\mathrm{PAH}$, which could result in sudden death and greatly increase the maternal and fetal risk. Consequently, we performed cardiac operations during pregnancy to maintain the pregnancy and to decrease the risk of adverse feto-neonatal outcomes. Other indications were life-threatening diseases, such as severe MS/AR, infective endocarditis,aortic dissection (Stanford type A), obstruction and thrombosis of the prosthetic valve. All patients were alive,and 3 cases had complicated arrhythmia after operations, especially atrial fibrillation. There were no other complications. The results indicate that cardiac operations can be performed during pregnancy with remarkable safety for mothers.

Pregnant women who have cardiac operations requiring $\mathrm{CPB}$ must face a nonphysiologic hemodynamic status where the tolerance is not clearly known, which can adversely affect the fetus [4]. CPB can compromise utero-placental perfusion and fetal development by potential adverse effects such as coagulation and blood component alterations, the release of vasoactive substances from leukocytes, complement activation, particulate and air embolism, nonpulsatile flow, hypothermia 
Table 2 Cardiac surgical procedure, intraoperatory parameters and fetal outcomes

\begin{tabular}{|c|c|c|c|c|c|c|c|}
\hline Patient No. & Cardiac surgical procedure & $\begin{array}{l}\text { Size of the cardiac } \\
\text { valves/defects }(\mathrm{mm})\end{array}$ & $\begin{array}{l}\text { Aortic cross- } \\
\text { clamp time } \\
\text { (minutes) }\end{array}$ & $\begin{array}{l}\text { CPB time } \\
\text { (minutes) }\end{array}$ & $\begin{array}{l}\mathrm{CPB} \\
\text { maximum } \\
\text { flow }(\mathrm{L})\end{array}$ & $\begin{array}{l}\text { CPB } \\
\text { minimum } \\
\text { temperature } \\
\left({ }^{\circ} \mathrm{C}\right)\end{array}$ & Fetal outcomes \\
\hline 1 & atrial septal defect closure & 45 & 10 & 40 & 3.7 & 35.8 & term birth, alive \\
\hline 2 & $\begin{array}{l}\text { mitral and tricuspid valve } \\
\text { repair }\end{array}$ & / & 60 & 96 & 5.8 & 35.3 & term birth, alive \\
\hline 3 & $\begin{array}{l}\text { right ventricle outlet } \\
\text { obstructio-n repair }\end{array}$ & / & 20 & 47 & 4.7 & 35.4 & preterm birth, alive \\
\hline 4 & MVR & 27 & 47 & 75 & 4.5 & 36 & termination of pregnancy \\
\hline 5 & MVR & 25 & 66 & 102 & 5.5 & 35.5 & term birth, alive \\
\hline 6 & MVR & 25 & 31 & 52 & 5 & 36.5 & preterm birth, alive \\
\hline 7 & $\begin{array}{l}\text { MVR+ atrial septal } \\
\text { defect closure }\end{array}$ & $27 / 13$ & 35 & 62 & 4.5 & 35.7 & preterm birth, alive \\
\hline 8 & AVR & 24 & 75 & 112 & 4.6 & 34.4 & term birth, alive \\
\hline 9 & $\begin{array}{l}\text { prosthetic mitral valve } \\
\text { thrombect-omy + mitr-al } \\
\text { valve repair }\end{array}$ & / & 101 & 133 & 4.9 & 34.8 & $\begin{array}{l}\text { abnormity of the brain, } \\
\text { termination of pregnancy }\end{array}$ \\
\hline 10 & atrial septal defect closure & 35 & 18 & 35 & 3.5 & 34.9 & term birth, alive \\
\hline 11 & MVR & 23 & 120 & 170 & 4.8 & 30 & term birth, alive \\
\hline 12 & $\begin{array}{l}\text { ventricula-r septal defect } \\
\text { closure }\end{array}$ & 13.8 & 30 & 72 & 4.5 & 35.1 & term birth, alive \\
\hline 13 & atrial septal defect closure & 21.7 & 21 & 40 & 4.2 & 35.8 & term birth, alive \\
\hline 14 & AVR & 19 & 95 & 122 & 5 & 34.7 & preterm birth,death \\
\hline 15 & $\begin{array}{l}\text { ventricula-r septal defect } \\
\text { closure+ AVR }\end{array}$ & $16.3 / 23$ & 78 & 97 & 5.2 & 36.6 & term birth, alive \\
\hline 16 & atrial septal defect closure & 30 & 13 & 25 & 4.5 & 36.2 & term birth, alive \\
\hline 17 & Betall procedure & / & 172 & 241 & 4.5 & 30 & death in utero \\
\hline 18 & MVR & 29 & 32 & 57 & 4.4 & 36.3 & death in utero \\
\hline 19 & MVR & 25 & 31 & 52 & 4.98 & 36 & preterm birth, death \\
\hline 20 & $\begin{array}{l}\text { atrial septal defect closure+ } \\
\text { ventricula-r septal defect } \\
\text { closure }\end{array}$ & $12 / 25$ & 35 & 74 & 4.3 & 34.1 & death in utero \\
\hline 21 & $\begin{array}{l}\text { ruptured sinus of Valsalva } \\
\text { repair+ valves thrombect-omy }\end{array}$ & / & 163 & 211 & 4.1 & 33.1 & termination of pregnancy \\
\hline 22 & $\begin{array}{l}\text { prosthetic aortic valve } \\
\text { thrombect-omy }\end{array}$ & / & 65 & 174 & 4.0 & 17.7 & death in utero \\
\hline
\end{tabular}

mm Millimetre, $L$ Litre, CPB Cardiopulmonary bypass, AVR Aortic valve replacement, MVR Mitral valve replacement

Table 3 Summary of indications for cardiac operation

\begin{tabular}{ll}
\hline Indication & $\mathrm{n}(\%)$ \\
\hline Congenital heart defect & $8(36.4 \%)$ \\
Rheumatic heart disease & $7(31.8 \%)$ \\
Infective endocarditis & $2(9.1 \%)$ \\
Aortic dissection & $1(4.5 \%)$ \\
Obstruction and thrombosis of prosthetic valve & $4(18.2 \%)$ \\
\hline
\end{tabular}

and hypotension [2].Three main pathophysiological changes can occur in pregnant patients under CPB: uterine contraction, placental hypo-perfusion and fetal hypoxia. Utero-placental hypo-perfusion and fetal hypoxia subjected to sustained uterine contractions during CPB are considered risk factors for fetal death [9]. Despite the limited experimental data regarding the effect of $\mathrm{CPB}$ on uterine/placental blood flow and its effect on the fetus, it has been postulated that pulsatile, high-flow, high-pressure, normothermic bypass poses the least risk to the fetus $[10,11]$.According to the above theories we 
Table 4 Feto-neonatal outcomes and mode of delivery

\begin{tabular}{|c|c|c|}
\hline Mode of delivery & $n(\%)$ & Feto-neonatal outcome \\
\hline Cesarean section & $14(63.6 \%)$ & $\begin{array}{l}14 \text { fetuses were alive without any abnormity ( } 9 \text { fetuses were term deliveries, and the other } \\
5 \text { were preterm deliveries). } \\
\text { One fetus manifested intracranial hemorrhage at } 36 \text { weeks of gestation and died after birth }\end{array}$ \\
\hline Induced labor (vaginal delivery) & $1(4.5 \%)$ & Neonatal intracranial hemorrhage and died after birth \\
\hline Spontaneous abortion & $4(18.2 \%)$ & Intrauterine death after operation \\
\hline Termination of pregnancy & $3(13.6 \%)$ & $\begin{array}{l}1 \text { fetus was detected abnormity of the brain. } \\
2 \text { patients abandoned pregnancy }\end{array}$ \\
\hline
\end{tabular}

applied high-flow, high-pressure, normothermic bypass to the patients and shortened the operation time to greatly decrease the influence on the fetus. Finally,the fetuses gained good outcomes,and the mortality rate was $18.2 \%$, lower than that reported in recent literature. Fourteen fetuses were alive and born without any abnormity. Unfortunately, two fetuses suffered neonatal intracranial hemorrhage and died after birth. However, we do not think it was associated with the operation or the $\mathrm{CPB}$ during pregnancy. The inappropriate use of Warfarin after operations was the main cause. The results indicate that cardiac operations can be performed during pregnancy with a degree of safety for fetus.

\section{Conclusion}

In conclusion, the decision to subject a pregnant woman to operation must be made by a team composed of an obstetrician, a cardiologist, an anesthesiologist and a neonatologist. Cardiac operation under CPB during pregnancy is a challenge for physicians in multidisciplinary teams. Strictly evaluating the indication is vital. On the other hand, some patients can benefit from this form of case management.

\section{Abbreviations}

y: Year; kg: Kilogram; w: Week; S: Singleton; T: Twin; mm: Millimetre; L: Litre; ASD: Atrial septal defect; VSD: Ventricular septal defect; MR: Mitral valve regurgitation; DCRV: Double cavity of right ventricle; MS: Mitral valve stenosis; AR: Aortic valve regurgitation; IE: Infective endocarditis; MR: Mitral valve regurgitation; PAH: Pulmonary artery hypertension; AD: Aortic dissection; AS: Aortic valve stenosis; AVR: Aortic valve replacement; MVR: Mitral valve replacement; SD: Standard deviation; CPB: Cardiopulmonary bypass

\section{Acknowledgements}

The authors gratefully acknowledge the physicians involved in the treatment, as well as the financial supports.

\section{Authors' contributions}

Yanli Liu: design the study, collect and analyze the data and write the paper. Fengzhen Han: design the study and explain the data. Jian Zhuang: financial and professional support. Xiaoqing Liu: professional support. Jimei Chen: financial and professional support. Huanlei Huang: professional support. Sheng Wang: professional support. Chengbin Zhou: professional support. The author(s) read and approved the final manuscript.

\section{Funding}

This work was supported by the Chinese National Key Research and Development Program [2018YFC1002600],the Science and Technology Department of Guangdong Province [No.

2014A050503048,2017A070701013,2017B090904034 and

2017B030314109,2019B3020230003], Guangdong Peak Project [No.
DFJH201802] and Guangdong Provincial Key Laboratory of South China Structural Heart Disease.

Availability of data and materials

The data were presented in the main manuscript.

Ethics approval and consent to participate

The authors certify that they have obtained all appropriate patient consent forms and also have abided by the statement of ethical standards.

Consent for publication

All of the authors agree to the publication of the article.

Competing interests

The authors have no conflicts of interest.

\section{Author details}

'Department of Obstetrics, Guangdong Provincial People's Hospital, Guangdong Academy of Medical Sciences, No. 106 Zhongshan 2nd road, Guangzhou 510080, Guangdong, China. ${ }^{2}$ Department of Cardiovascular Surgery, Guangdong Cardiovascular Institute, Guangdong Provincial Key Laboratory of South China Structural Heart Disease, Guangdong Provincial People's Hospital, Guangdong Academy of Medical Sciences, Guangzhou, Guangdong, China. ${ }^{3}$ Department of Epidemiology, Guangdong

Cardiovascular Institute, Guangdong Provincial Key Laboratory of South China Structural Heart Disease, Guangdong Provincial People's Hospital, Guangdong Academy of Medical Sciences, Guangzhou, Guangdong, China ${ }^{4}$ Department of Anesthesia, Guangdong Provincial People's Hospital, Guangdong Academy of Medical Sciences, Guangzhou, Guangdong, China.

Received: 23 December 2019 Accepted: 4 May 2020

Published online: 13 May 2020

\section{References}

1. Simpson LL. Maternal cardiac disease: update for the clinician. Obstet Gynecol. 2012;119(2 Pt 1):345-59. https://doi.org/10.1097/AOG. Ob013e318242e260.

2. Chambers CE, Clark SL. Cardiac surgery during pregnancy. Clin Obstet Gynecol. 1994:37:316-23.

3. Hurst JW. The value of using the entire New York heart Association's classification of heart and vascular disease. Clin Cardiol. 2006;29:415-7.

4. Mahli A, Izdes S, Coskun D. Cardiac operations during pregnancy: review of factors influencing fetal outcome. Ann Thorac Surg. 2000 May;69(5):1622-6. https://doi.org/10.1016/S0003-4975(00)01178-4.

5. Leyse R, Ofstun M, Dillard DH, Merendino KA. Congenital aortic stenosis in pregnancy, corrected by extracorporeal circulation: offering a viable male infant at term but with anomalies eventuating in this death at four months of age-report of case. JAMA. 1961;176:1009-12.

6. Becker RM. Intracardiac surgery in pregnant women. Ann Thorac Surg. 1983; 36:453-8.

7. Gopal K, Hudson IM, Ludmir J, Braffman MN, Ewing S, Bavaria JE, Wong KL, Bridges CR. Homograft aortic root replacement during pregnancy. Ann Thorac Surg. 2002;74(1):243-5. https://doi.org/10.1016/S0003-4975(02)03590-7.

8. Jantzen J-P, Bader W. The cardiac risk patient presenting for gynecological surgery. Geburtshilfe Frauenheilkd. 2011;71:183-6.

9. Yuan SM. Indications for cardiopulmonary bypass during pregnancy and impact on fetal outcomes. Geburtshilfe Frauenheilkd. 2014 Jan;74(1):55-62. https://doi.org/10.1055/s-0033-1350997. 
10. Westaby S, Parry AJ, Forfar JC. Reoperation for prosthetic valve endocarditis in the third trimester of pregnancy. Ann Thorac Surg. 1992;53:263-5. https:// doi.org/10.1016/0003-4975(92)91329-8.

11. Pomini F, Mercogliano D, Cavalletti C, Caruso A, Pomini P. Cardiopulmonary bypass in pregnancy. Ann Thorac Surg. 1996;61:259-68. https://doi.org/10. 1016/0003-4975(95)00818-7.

\section{Publisher's Note}

Springer Nature remains neutral with regard to jurisdictional claims in published maps and institutional affiliations.

Ready to submit your research? Choose BMC and benefit from:

- fast, convenient online submission

- thorough peer review by experienced researchers in your field

- rapid publication on acceptance

- support for research data, including large and complex data types

- gold Open Access which fosters wider collaboration and increased citations

- maximum visibility for your research: over $100 \mathrm{M}$ website views per year

At BMC, research is always in progress.

Learn more biomedcentral.com/submissions 